\title{
Association between cystographic anastomotic urinary leakage following retropubic radical prostatectomy and early urinary incontinence
}

\author{
Se Yun Kwon \\ Department of Urology, Dongguk University College of Medicine, Gyeongju, Korea
}

Received: July 30, 2020

Revised: October 12, 2020

Accepted: October 12, 2020

Corresponding author:

Se Yun Kwon, MD, PhD

Department of Urology, Dongguk

University College of Medicine, 87

Dongdae-ro, Gyeongju 38067,

Korea

Tel: +82-54-770-8565

Fax: +82-54-770-8378

E-mail: urodrksy@gmail.com
Background: This study was performed to investigate the association between cystographic anastomotic urinary leakage (UL) after retropubic radical prostatectomy (RRP) and early urinary incontinence (UI).

Methods: The medical records of 53 patients who had undergone cystography after RRP at our institution between January 2015 and December 2018 were retrospectively analyzed. Cystography was performed 7 to 10 days after surgery. The duration of catheterization depended on the degree of $U L$, which was classified as mild, moderate, or severe. The study subjects were divided into the non-UL group and the UL group. Continence was defined as the use of no pads. The prostate was dissected in an antegrade fashion, and urethrovesical anastomosis was performed with a continuous suture.

Results: Incontinence rates at 1 and 3 months postoperatively were significantly higher in the UL group than the non-UL group ( $83.3 \%$ vs. $52.2 \%, p=0.014$ and $76.7 \%$ vs. $47.8 \%, p=0.030$, respectively); however, those at 6 and 12 months were not significantly different (23.3\% vs. $17.4 \%$, $p=0.597$ and $4.3 \%$ vs. $10.0 \%, p=0.440$, respectively). The severity of UL was not found to influence the duration of incontinence. The presence of cystographic anastomotic UL was found to be predictive of UI during the first 3 postoperative months (odds ratio, 3.3; $p=0.045$ ).

Conclusion: The presence of anastomotic UL on cystography was associated with higher rates of $\mathrm{UI}$ in the early postoperative periods. However, incontinence rates in patients with or without anastomotic UL immediately after RRP equalized at 6 months and the severity of UL did not affect the duration of postoperative UI.

Keywords: Anastomotic leak; Prostatectomy; Urinary incontinence

\section{Introduction}

Retropubic radical prostatectomy (RRP) is now established as the gold standard surgical management for localized prostate cancer $[1,2]$. However, the role of RRP has become more complex because a greater focus has been placed on patient- and cancer-specific considerations, especially those related to the balance between oncologic and functional outcomes. Unfortunately, the majority of patients who undergo RRP for prostate cancer experience treatment-related complications, especially postprostatectomy urinary incontinence (PPUI), which has a significant impact on patient quality of life [3].

RRP involves removal of the prostate and formation of a new connection between the urethra and bladder. Prostate removal is achieved by antegrade or retrograde processing, and anastomosis between the urethra and bladder is performed using a continuous

Copyright (C) 2021 Yeungnam University College of Medicine

This is an Open Access article distributed under the terms of the Creative Commons Attribution Non-Commercial License (http://creativecommons.org/licenses/by-nc/4.0/) which permits unrestricted non-commercial use, distribution, and reproduction in any medium, provided the original work is properly cited. 
or interrupted suture. In the case of open RRP, an interrupted suture is usually used, but the widespread use of laparoscopy has contributed to the proportion of procedures conducted using a continuous suture [4].

In general, cystography is performed between 1 and 2 weeks after RRP to confirm urinary leakage (UL) at the anastomosis site. One of the most common short-term complications of RRP is UL [5]. In several studies, the incidence of UL has been reported to be as high as $10 \%$ [6]. The consensus opinion is that UL does not seem to affect long-term PPUI, but early continence may be delayed due to UL, and patients with anastomotic leakage have a higher incidence of PPUI $[7,8]$. However, it remains unclear how the degree of UL affects urinary incontinence after RRP, and no reports on this relationship have been published in Korea.

We retrospectively analyzed the incidence and severity of UL in 53 patients who had undergone RRP at our center. These patients were divided into two groups based on the presence or absence of anastomotic UL immediately after surgery and compared with respect to possible factors responsible for UL. Moreover, the association between UL and PPUI was investigated.

\section{Materials and methods}

\section{Study design and patient enrollment}

After the approval of the Institutional Review Board (IRB) and Ethics Committee of Dongguk University College of Medicine (IRB No: 1107-201903-HR-03-02), 53 consecutive patients with a diagnosis of prostate cancer who had undergone RRP at our institution between January 2015 and December 2018 were enrolled in this study. Informed consent was waived by the IRB.

\section{Variables inspected}

Data were obtained by retrospective chart review. The variables analyzed included age, body mass index (BMI), prostate volume, operative time, estimated blood loss, duration of catheter indwelling, presence or absence of UL on postoperative cystography, and pathologic variables (i.e., preoperative prostate-specific antigen [PSA] level, postoperative Gleason score, and pathologic stage).

Cystography was performed 7 to 10 days after surgery. Normal saline (up to $200 \mathrm{~mL}$ ) was injected to check for UL. The duration of catheterization depended on the degree of UL, which was classified as mild, moderate, or severe. UL was defined as mild when leakage was observed after injecting $200 \mathrm{~mL}$, moderate if observed after injecting $100 \mathrm{~mL}$, and severe if leakage occurred before injecting $100 \mathrm{~mL}$ normal saline (Fig. 1).

In cases of mild UL, the catheter was removed after 3 days, and for moderate UL, it was removed after 7 days [9]. In cases of severe UL, cystography was repeated at 7-day intervals with the catheter in situ until the UL ceased. The 53 study subjects were divided into two groups; the non-UL group $(n=23)$ and the UL group $(n=30)$.

\section{Definition and assessment of continence}

Continence was defined as no pad usage, as determined by patient response. Patients were asked the following question; "How many pads or adult diapers have you used daily to control leakage during the past 4 weeks?" Continence recovery was evaluated routinely at $1,3,6$, and 12 months after RRP.

\section{Surgical technique}

RRP was performed in the supine position. The superficial dorsal vein was coagulated by bipolar ablation, and periprostatic fat was removed. Before disassembling the bladder and prostate, both lat-
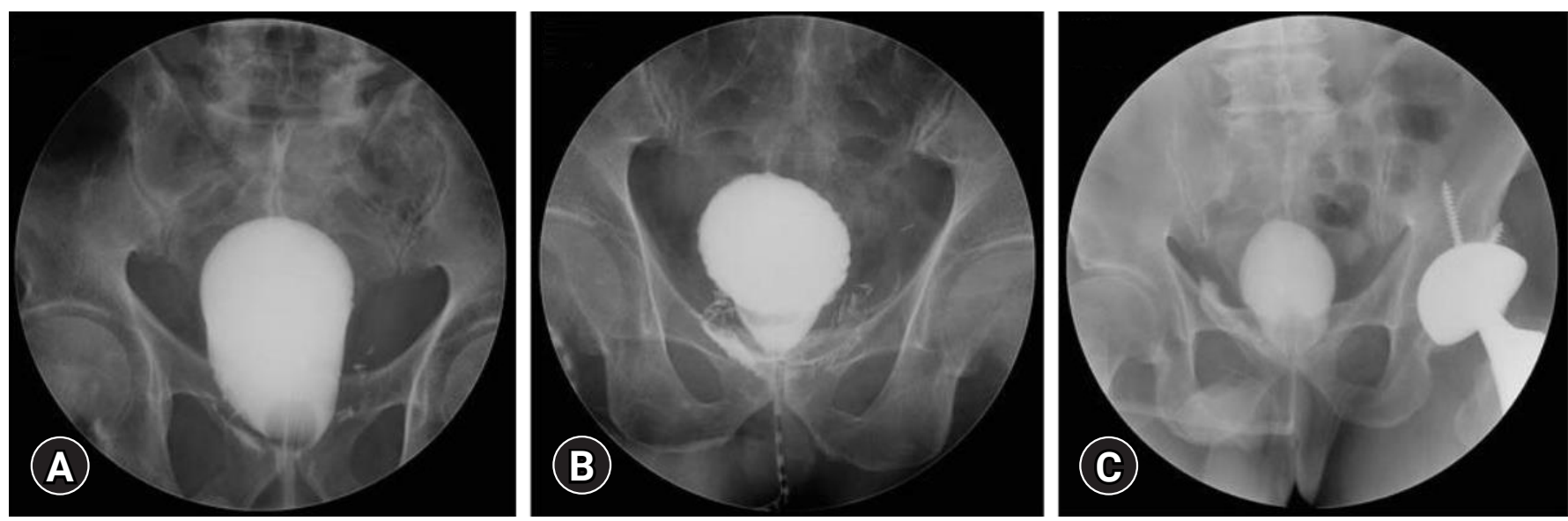

Fig. 1. Cystography findings and classification of urinary leakage (UL). (A) Mild UL (UL developed after bladder filling with $200 \mathrm{~mL}$ normal saline). (B) Moderate UL (UL developed after bladder filling with $100 \mathrm{~mL}$ normal saline). (C) Severe UL (UL developed before bladder filling with $100 \mathrm{~mL}$ normal saline). 
eral outer borders of the bladder and prostate were dissected and a cut was placed along the imaginary bladder-prostate borderline. After dissecting vas deferens and seminal vesicles, the prostate was dissected in an antegrade fashion while preserving the bilateral nerves, and hemostasis was conducted carefully. A double-stranded running suture was then placed bidirectionally from 6 o'clock to 3 and 9 o'clock and then from 3 o'clock to 9 and 12 o'clock while maintaining tension at the posterior anastomosis site to achieve anastomosis with a Monosyn 3.0 (Aesculap, Melsungen AG, Germany) suture. A catheter was then inserted, and a $120-\mathrm{mL}$ saline filling test was conducted to confirm the absence of leakage.

\section{Statistical analysis}

The chi-square test and the Mann-Whitney test were used to analyze the demographics and perioperative outcomes. Incontinence rates at $1,3,6$, and 12 months after surgery were analyzed using the chi-square test. Logistic regression analysis was used to identify factors that independently affected incontinence. PASW Statistics version 18.0 (IBM Corp., Armonk, NY, USA) was used for the analysis. For all comparisons, $p$-values of $<0.05$ were considered statistically significant.

\section{Results}

Fifty-three patients who had undergone RRP were included in the study. The mean patient age was 68.8 years (range, $67-70$ years), mean BMI was $24.5 \pm 2.9 \mathrm{~kg} / \mathrm{m}^{2}$, and mean prostate size was $40.1 \pm 18.6 \mathrm{~mL}$. Six patients $(11.3 \%)$ had a preoperative PSA $>20$ $\mathrm{ng} / \mathrm{mL}$, and pathological organ-confined disease was observed in 31 patients $(58.5 \%)$.

UL was detected during postoperative cystography inspections in 30 patients (56.6\%); six had mild, 12 had moderate, and 12 had severe leakage. The longest period of catheterization was 38 days, which was observed in three patients. These three patients were evaluated for incontinence 1 month after removal of the Foley catheter. The mean catheterization periods for mild, moderate, and severe UL were 13.0, 17.0, and 20.1 days, respectively.

Times to catheter removal were significantly different between UL and non-UL groups $(9.7 \pm 0.9$ vs. $20.6 \pm 7.5, p=0.001)$ (Table 1$)$. However, other perioperative characteristics and outcomes were similar. Furthermore, no significant intergroup difference was observed for pathologic data, including pathologic stage, mean Gleason score, and positive surgical margin (Table 1).

Incontinence rates at 1 and 3 months postoperatively were significantly different between UL and non-UL groups ( $83.3 \%$ vs. $52.2 \%, p=0.014$ and $76.7 \%$ vs. $47.8 \%, p=0.030$, respectively), but no significant difference was observed at 6 months (Table 2). The degree of UL was not found to influence the duration of incontinence (Table 2). In patients with severe UL, the incontinence rate at 12 months was $16.7 \%$.

By logistic regression analysis, anastomotic UL was found to be the only significant predictor of urinary incontinence (odds ratio,

Table 1. Perioperative characteristics and outcomes between urinary leakage (UL) and non-UL group

\begin{tabular}{|c|c|c|c|}
\hline Characteristic & UL group $(n=30)$ & Non-UL group $(n=23)$ & $p$-value \\
\hline Age $(y r)$ & $69.1 \pm 4.8$ & $68.4 \pm 5.9$ & 0.649 \\
\hline Body mass index $\left(\mathrm{kg} / \mathrm{m}^{2}\right)$ & $25.1 \pm 2.9$ & $23.6 \pm 2.6$ & 0.059 \\
\hline Prostate volume $(\mathrm{mL})$ & $41.0 \pm 21.5$ & $39.0 \pm 14.4$ & 0.709 \\
\hline Preoperative PSA (ng/mL) & $10.4 \pm 9.0$ & $9.8 \pm 9.2$ & 0.830 \\
\hline Mean operative time (min) & $218.6 \pm 33.5$ & $193.1 \pm 43.8$ & 0.088 \\
\hline Estimated blood loss (mL) & $284.7 \pm 129.8$ & $268.2 \pm 143.0$ & 0.664 \\
\hline Catheterization (day) & $20.6 \pm 7.5$ & $9.7 \pm 0.9$ & 0.001 \\
\hline Pathologic stage & & & 0.152 \\
\hline $\mathrm{T} 2$ & $15(50.0)$ & 7 (30.4) & \\
\hline T3 & $15(50.0)$ & $16(69.6)$ & \\
\hline Pathologic Gleason score & & & 0.615 \\
\hline 6 & 0 & $2(8.7)$ & \\
\hline 7 & $14(46.7)$ & $12(52.2)$ & \\
\hline 8 & $7(23.3)$ & $2(8.7)$ & \\
\hline 9 & $9(30.0)$ & $6(26.1)$ & \\
\hline 10 & 0 & $1(4.3)$ & \\
\hline Positive surgical margin & $8(26.7)$ & $8(34.8)$ & 0.524 \\
\hline
\end{tabular}

Values are presented as mean \pm standard deviation or number (\%).

PSA, prostate-specific antigen. 
3.3; 95\% confidence interval, $0.973-11.207 ; p=0.045$ ) (Table 3). There were no significant factor of PPUI at 6 and 12 months (Tables 4, 5).

\section{Discussion}

PPUI is a major complication of RRP and has a substantial impact on patient's quality of life because it affects physical activity and social well-being. The reported incidence of PPUI varies from $4 \%$ to $69 \%[9,10]$, depending on multiple factors such as age, preoperative voiding status, sphincteric functional competence, perioperative bladder function, and operative factors [10-13].

The pathophysiology of PPUI is not fully understood, although several studies have suggested that intrinsic bladder sphincter deficiency, underactivity, neural injury $[14,15]$, defects in urethral support [16], shortening of membranous urethral length, and venous

Table 2. Incontinence rates between urinary leakage (UL) and nonUL group from 1 to 12 months and comparison of incontinence rates based on the degree of leakage

\begin{tabular}{|c|c|c|c|c|}
\hline \multirow{2}{*}{ Variable } & \multicolumn{4}{|c|}{ Incontinence rate } \\
\hline & $1 \mathrm{Mo}$ & $3 \mathrm{Mo}$ & $6 \mathrm{Mo}$ & $12 \mathrm{Mo}$ \\
\hline \multicolumn{5}{|l|}{ Group } \\
\hline Non-UL group $(n=23)$ & 12 (52.2) & $11(47.8)$ & $4(17.4)$ & $1(4.3)$ \\
\hline UL group $(n=30)$ & 25 (83.3) & $23(76.7)$ & 7 (23.3) & $3(10.0)$ \\
\hline$p$-value & 0.014 & 0.030 & 0.597 & 0.440 \\
\hline \multicolumn{5}{|l|}{ Degree of leakage ${ }^{a)}$} \\
\hline Mild $(n=6)$ & $4(66.7)$ & $4(66.7)$ & $3(50.0)$ & 0 \\
\hline Moderate $(n=12)$ & $11(91.7)$ & 10 (83.3) & $1(8.3)$ & $1(8.3)$ \\
\hline Severe $(n=12)$ & 10 (83.3) & $9(75.0)$ & $3(25.0)$ & $2(16.7)$ \\
\hline$p$-value $e^{b)}$ & 0.066 & 0.157 & 0.209 & 0.519 \\
\hline
\end{tabular}

Values are presented as number (\%).

a) Mild, leakage occurred after injecting $200 \mathrm{~mL}$ normal saline (NS); moderate, leakage occurred after injecting $100 \mathrm{~mL} \mathrm{NS}$; severe, leakage

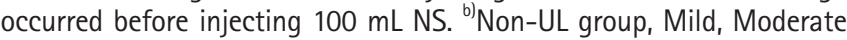
and Severe UL group were analyzed by chi-square test.

Table 3. Multivariate logistic regression analysis for factors of postprostatectomy urinary incontinence at 3 months

\begin{tabular}{lcc}
\hline Variable & OR $(95 \% \mathrm{Cl})$ & $p$-value \\
\hline Age & $1.044(0.925-1.179)$ & 0.483 \\
Body mass index & $1.250(0.955-1.637)$ & 0.105 \\
Prostate-specific antigen & $1.019(0.939-1.105)$ & 0.655 \\
Pathologic T stage & $1.204(0.293-4.945)$ & 0.796 \\
Gleason score & $1.160(0.585-2.298)$ & 0.671 \\
Prostate size & $1.006(0.970-1.043)$ & 0.754 \\
Duration of catheterization & $1.317(0.733-2.366)$ & 0.357 \\
Degree of leakage & $1.213(0.105-8.551)$ & 0.111 \\
Urinary leakage & $3.301(0.973-11.207)$ & 0.045 \\
\hline
\end{tabular}

$\mathrm{OR}$, odds ratio; $\mathrm{Cl}$, confidence interval. sealing effects underlie the condition $[17,18]$. Research efforts have resulted in several surgical advances, especially the nerve-saving technique, which was recently evaluated in a large European patient cohort [19].

Although UL does not seem to affect long-term incontinence, it has been associated with early PPUI $[7,8]$. Consistently, in this study, the incontinence rates were significantly higher in the UL group compared to the non-UL group during the first 3 postoperative months; however, no significant intergroup difference was observed at 6 months postoperatively. Furthermore, anastomotic UL was identified as a significant prognostic factor of urinary incontinence in the early postoperative period following RRP. These findings indicate that given the absence of UL through a defective anastomotic site, adequate urinary drainage after RRP is essential to promote healing of the vesicourethral anastomosis.

In the current study, the proportion of cases with UL after RRP (56.6\%) was higher than has been previously reported [20,21]. At our center, in cases of UL post-RRP, the Foley catheter is removed at 1 to 2 weeks postoperatively, depending on the degree of UL.

Table 4. Multivariate logistic regression analysis for factors of PPUI at 6 months

\begin{tabular}{lclc}
\hline Variable & OR & \multicolumn{1}{c}{$95 \% \mathrm{Cl}$} & $p$-value \\
\hline Age & 1.080 & $0.908-1.284$ & 0.386 \\
Body mass index & 1.098 & $0.843-1.431$ & 0.486 \\
PSA & 0.965 & $0.868-1.072$ & 0.506 \\
Pathologic T stage & 5.730 & $0.753-43.626$ & 0.092 \\
Gleason score & 0.409 & $0.133-1.252$ & 0.117 \\
Prostate size & 1.018 & $0.981-1.056$ & 0.344 \\
Duration of catheterization & 1.211 & $0.937-1.565$ & 0.143 \\
Degree of leakage & 0.082 & $0.003-2.577$ & 0.155 \\
Urinary leakage & 0.107 & $0.008-1.425$ & 0.091 \\
\hline
\end{tabular}

$\mathrm{PPUI}$, postprostatectomy urinary incontinence; $\mathrm{OR}$, odds ratio; $\mathrm{Cl}$, confidence interval; PSA, prostate specific antigen.

Table 5. Multivariate logistic regression analysis for factors of PPUI at 12 months

\begin{tabular}{lclc}
\hline Variable & $\mathrm{OR}$ & \multicolumn{1}{c}{$95 \% \mathrm{Cl}$} & $p$-value \\
\hline Age & 1.015 & $0.702-1.466$ & 0.939 \\
Body mass index & 2.111 & $0.832-5.359$ & 0.116 \\
PSA & 1.101 & $0.877-1.381$ & 0.407 \\
Pathologic T stage & 2.985 & $0.094-94.440$ & 0.535 \\
Gleason score & 2.743 & $0.267-28.200$ & 0.396 \\
Prostate size & 0.862 & $0.636-1.168$ & 0.339 \\
Duration of catheterization & 0.696 & $0.293-1.652$ & 0.412 \\
Degree of leakage & 570.906 & $0.003-7.853$ & 0.178 \\
Urinary leakage & 600.972 & $0.042-2.647$ & 0.177 \\
\hline
\end{tabular}

PPUI, postprostatectomy urinary incontinence; $\mathrm{OR}$, odds ratio; $\mathrm{Cl}$, confidence interval; PSA, prostate specific antigen. 
Thus, sphincter function at the anastomosis site is likely to be abnormal during the early period. All of our patients received continuous anastomosis, and thus, approximation was more precise than that achieved using interrupted sutures. Leakage is more likely in incompletely sutured regions when interrupted sutures are used but may also occur due to loosening of the approximation with continuous anastomosis. If the Foley catheter indwelling period is sufficient, contracture is less likely during healing, and the healing period is reduced. However, when continuous suturing is performed using an open approach, the distance between 5 and 7 o'clock in the posterior anastomosis area tends to be greater than that in the anterior anastomosis area. This might have contributed to the higher prevalence of UL after RRP in the present study. Since RRP cases were performed by a single surgeon with less than 60 cases of experience, it was also considered a very important cause.

There were 12 patients with severe UL, and 2 (16.7\%) of them experienced mild incontinence 1 year after RRP. These patients used only one pad per day and had no obstructive symptoms, such as a weak urine stream or hesitancy, which are the main symptoms of bladder neck contracture. Despite a short follow-up period, we were able to conclude that serious UL did not necessarily cause bladder neck contracture.

This study is limited by its retrospective, single-center design, and relatively small sample size. In fact, many factors affect PPUI, including the length of the preserved urethra after surgery, preservation of the bladder neck, sphincter injury, and preoperative voiding status. However, our study shows that postoperative cystographic UL does not develop into long-term incontinence and that in this era of robotic surgery, a continuous anastomosis suture procedure can be adopted during open RRP. No association has been previously reported between incontinence and urethrovesical anastomosis leakage in Korea.

Cystographically detected anastomotic UL was associated with higher rates of early urinary incontinence. However, continence rates were much improved 6 months after RRP in patients with anastomotic UL after surgery and the severity of UL did not affect the duration of postoperative UI.

\section{Acknowledgments}

\section{Conflicts of interest}

No potential conflict of interest relevant to this article was reported.

\section{ORCID}

Se Yun Kwon, https://orcid.org/0000-0003-1147-8037

\section{References}

1. Holmberg L, Bill-Axelson A, Helgesen F, Salo JO, Folmerz P, Häggman $\mathrm{M}$, et al. A randomized trial comparing radical prostatectomy with watchful waiting in early prostate cancer. $\mathrm{N}$ Engl J Med 2002;347:781-9.

2. Walsh PC. Anatomic radical prostatectomy: evolution of the surgical technique. J Urol 1998;160(6 Pt2):2418-24.

3. Sanda MG, Dunn RL, Michalski J, Sandler HM, Northouse L, Hembroff L, et al. Quality of life and satisfaction with outcome among prostate-cancer survivors. N Engl J Med 2008;358: 1250-61.

4. Lim JH, Park CM, Kim HK, Park JY. Comparison of perioperative outcomes between running versus interrupted vesicourethral anastomosis in open radical prostatectomy: a single-surgeon experience. Korean J Urol 2015;56:443-8.

5. Tyritzis SI, Katafigiotis I, Constantinides CA. All you need to know about urethrovesical anastomotic urinary leakage following radical prostatectomy.J Urol 2012;188:369-76.

6. Mochtar CA, Kauer PC, Laguna MP, de la Rosette JJ. Urinary leakage after laparoscopic radical prostatectomy: a systematic review.J Endourol 2007;21:1371-9.

7. Patil N, Krane L, Javed K, Williams T, Bhandari M, Menon M. Evaluating and grading cystographic leakage: correlation with clinical outcomes in patients undergoing robotic prostatectomy. BJU Int 2009; 103:1108-10.

8. Webb DR, Sethi K, Gee K. An analysis of the causes of bladder neck contracture after open and robot-assisted laparoscopic radical prostatectomy. BJU Int 2009;103:957-63.

9. Cormio L, Di Fino G, Scavone C, Maroscia D, Mancini V, Ruocco N, et al. Prognostic factors for anastomotic urinary leakage following retropubic radical prostatectomy and correlation with voiding outcomes. Medicine (Baltimore) 2016;95:e3475.

10. Ficarra V, Novara G, Rosen RC, Artibani W, Carroll PR, Costello A, et al. Systematic review and meta-analysis of studies reporting urinary continence recovery after robot-assisted radical prostatectomy. Eur Urol 2012;62:405-17.

11. Ficarra V, Novara G, Artibani W, Cestari A, Galfano A, Graefen $\mathrm{M}$, et al. Retropubic, laparoscopic, and robot-assisted radical prostatectomy: a systematic review and cumulative analysis of comparative studies. Eur Urol 2009;55:1037-63.

12. Geraerts I, Van Poppel H, Devoogdt N, Van Cleynenbreugel B, Joniau S, Van Kampen M. Prospective evaluation of urinary incontinence, voiding symptoms and quality of life after open and robot-assisted radical prostatectomy. BJU Int 2013;112:93643.

13. Xu T, Wang X, Xia L, Zhang X, Qin L, Zhong S, et al. Robot-as- 
sisted prostatectomy in obese patients: how influential is obesity on operative outcomes? J Endourol 2015;29:198-208.

14. Kretschmer A, Hübner W, Sandhu JS, Bauer RM. Evaluation and management of postprostatectomy incontinence: a systematic review of current literature. Eur Urol Focus 2016;2:245-59.

15. John H, Sullivan MP, Bangerter U, Hauri D, Yalla SV. Effect of radical prostatectomy on sensory threshold and pressure transmission. J Urol 2000;163:1761-6.

16. Burnett AL, Mostwin JL. In situ anatomical study of the male urethral sphincteric complex: relevance to continence preservation following major pelvic surgery. J Urol 1998;160:1301-6.

17. Wei JT, Dunn RL, Marcovich R, Montie JE, Sanda MG. Prospective assessment of patient reported urinary continence after radical prostatectomy. J Urol 2000;164(3 Pt 1):744-8.
18. Lucas MG, Bosch RJ, Burkhard FC, Cruz F, Madden TB, Nambiar AK, et al. EAU guidelines on surgical treatment of urinary incontinence. Eur Urol 2012;62:1118-29.

19. Bue P, Holmberg AR, Márquez M, Westlin JE, Nilsson S, Malmström PU. Intravesical administration of EGF- dextran conjugates in patients with superficial bladder cancer. Eur Urol 2000; 38:584-9.

20. Varkarakis J, Wirtenberger W, Pinggera GM, Berger A, Harabayashi T, Bartsch G, et al. Evaluation of urinary extravasation and results after continence-preserving radical retropubic prostatectomy. BJU Int 2004;94:991-5.

21. Ramsden AR, Chodak GW. Can leakage at the vesico-urethral anastomosis be predicted after radical retropubic prostatectomy? BJU Int 2004;93:503-6. 